\title{
Noninfectious Complications in Children Undergoing Chronic Peritoneal Dialysis
}

Loza $\mathbf{R}^{\star}$ and Gutarra $\mathrm{E}$

Pediatric Department, Pediatric Nephrology Unit, Cayetano Heredia Hospital, Peritoneal Dialysis Unit, University Support Service, Cayetano Heredia University, Lima, Peru

*Corresponding author: Reyner loza Munarriz, Cayetano Heredia Hospital Lima, Lima, Peru, Tel: 513825906; E-mail: reyfe@hotmail.com

Rec date: Feb 16, 2014, Acc date: May 08, 2014, Pub date: May 15, 2014

Copyright: (C) 2014 Loza RM, et al. This is an open-access article distributed under the terms of the Creative Commons Attribution License, which permits unrestricted use, distribution, and reproduction in any medium, provided the original author and source are credited.

\begin{abstract}
Objectives: To describe the general characteristics and frequency of noninfectious complications in children with end stage renal disease (ESRD) in chronic peritoneal dialysis. Material and methods: A retrospective case series study describing noninfectious complications in the population of children, aged between 1 month and 17 years 11 months, with end stage renal disease from the peritoneal dialysis program at Cayetano Heredia Hospital between 2000 and 2007.

Results: We studied 80 children, 41 male and 39 female; 92 catheters were implanted; the average age of the children was 10.3 years and the largest age group was from 5 to 12 years. The leading cause of end stage renal disease was primary glomerulopathy. The Tenckhoff two-cuff spiral catheter was the most commonly used catheter; continuous ambulatory peritoneal dialysis was the most common mode of dialysis; there were 12 catheter replacements, the most frequent causes being peritonitis and catheter obstruction. The frequency of noninfectious complications was $40.3 \%$; the three most common complications were ultrafiltration failure (low transporter type), umbilical hernia, and catheter obstruction.
\end{abstract}

Conclusions: The frequency of noninfectious complications was $40.3 \%$; the most common complication was ultrafiltration failure.

Keywords: Noninfectious complications; Children; Peritoneal dialysis; Renal insufficiency; Chronic; Tenckhoff catheter

\section{Introduction}

Peritoneal dialysis (PD) is the preferred renal replacement therapy in children with end stage renal disease (ESRD). It has been used for renal replacement in children since 1978 and has been shown to have a number of advantages over hemodialysis - above all in children where the vascular access is difficult, in patients receiving anticoagulants, and in children without access to a hemodialysis center. PD also achieves better control of blood pressure, acidemia, and electrolyte balance. As a result, it is possible to achieve a higher degree of social and school rehabilitation at lower financial cost [1-6].

As well as advantages, there are also disadvantages, however. These are complications, which can be classified as infectious or noninfectious: noninfectious complications include complications with the surgical technique, catheter malfunction, defects in the abdominal wall, ultrafiltration failure, and electrolyte and metabolic complications. Studying and being familiar with these complications is important, as they imply therapy failure and an increase in financial costs [7-9].

No studies have been conducted on this subject in Peru. In Latin America, there have been two studies: one in Chile, describing the characteristics of the patients and their infectious complications, without reference to noninfectious complications; and a thesis in Brazil on surgical complications and related technical aspects. In addition, there have been a number of other studies in the world examining complications in general, with little emphasis on noninfectious complications [10-14].

The objectives of the present study were to describe the characteristics of the population of children with ESRD in chronic peritoneal dialysis and the frequency of noninfectious complications related to surgical technique, catheter malfunction, defects in the abdominal wall, and failure of ultrafiltration at the Peritoneal Dialysis Unit of Cayetano Heredia Hospital (CHH), Lima, Peru between 2000 and 2007.

\section{Materials and Methods}

A descriptive study was conducted, namely a retrospective case series study of the population of children with ESRD undergoing chronic peritoneal dialysis therapy at $\mathrm{CHH}$ between January 2000 and December 2007.

The criteria of inclusion were as follows: (1) children with a diagnosis of ESRD requiring chronic peritoneal dialysis; (2) age over 1 month and less than 18 years; (3) peritoneal dialysis catheter placement at $\mathrm{CHH}$.

Exclusion criteria were (1) children with ESRD in peritoneal dialysis referred from other hospitals; (2) placement of catheters without standardized techniques; (3) incomplete follow-up reports from the peritoneal dialysis unit.

Regarding placement of the PD catheter, for all children the catheter was put in place following the recommendations of the European Committee of the International Society for Elective Chronic 
Page 2 of 5

Peritoneal Dialysis in Pediatric Patients (34): type of surgery, minilaparotomy; general anesthesia; paramedian line catheter entry site, directing it downward and to the middle, with partial omentectomy. The procedure was performed by a pediatric surgeon; the interval between the placement of the catheter and the onset of dialysis was two weeks.

The instrument of data collection was previously elaborated; the source of information was the medical records from $\mathrm{CHH}$ and the patient's follow-up sheets at the Peritoneal Dialysis

Unit from the Support Services of Cayetano Heredia Peruvian University. We performed descriptive analysis means median and standard deviation to analyze the continued variables. The statistical program used was STATA version 11.

The general variables that allowed us to learn the most important characteristics of the population were: age upon entering peritoneal dialysis therapy, sex, primary diagnosis of ESRD, DP catheter, replacement of DP catheter, number of replacements of catheter, and omentectomy at the beginning of peritoneal dialysis.

The operational definition of variables and risk factors of noninfectious complications, excluding metabolic and electrolyte complications, was classified by reviewing the bibliographies in the following publications $[8,9,15]$.

\section{Noninfectious complications related to surgical technique:}

- Hemoperitoneum: Presence of blood in the peritoneal fluid. Causes: injury of blood vessels when placing the catheter, coagulation disorders, sclerosing peritonitis, splenic rupture.

- Chyloperitoneum: Appearance of milky turbid liquid with normal cell counts in the absence of peritonitis due to the presence of triglyceride rich chylomicrons. Causes: microtrauma of lymphatic vessels when inserting the catheter [16], malignant neoplasm [17], cirrhosis, chronic pancreatitis [18], systemic amyloidosis [19], lymphatic obstruction due to fibrous adhesions caused by tuberculosis, [20] and the use of dihydropyridine calcium antagonists [21].

- External cuff extrusion: Appearance of external cuff through the outlet port.

- Extrusion of the catheter: Presence of the catheter through the outlet port.

- Abdominal wall hematoma

\section{Noninfectious complications of catheter dysfunction:}

- Abdominal hernias: The protrusion of an organ or tissue outside the abdominal cavity.

Risk factors: history of prior abdominal surgery, polycystic kidney disease [22,23], persistence of the vaginal process [24], male and aged less than six months [25]. Types by location: umbilical, inguinal and incisional.

- Leakage of dialysate: Leakage of dialysate outside the abdominal cavity through different areas of weakness of the abdominal cavity, including the hydrothorax.

\section{Noninfectious complications due to ultrafiltration failure:}

- Ultrafiltration failure: The most accepted definition is a UF (ultrafiltration) less than $400 \mathrm{ml}$ with an exchange of $3.86 \%$ glucose and a dwell time of $4 \mathrm{~h}$ [26]. It is classified according to the estimation of transport of small molecular weight solutes in:

- High Transporters: Low volume of drainage and high transport of solutes (UF failure type I): patients with UF less than $400 \mathrm{ml}$ at 4 hours and a dialysate ratio plasma $(\mathrm{d} / \mathrm{p})$ of creatinine greater than 0.81 .

- Low transporters: Low volume of drainage and low peritoneal transport (UF failure type II): patients with UF less than $400 \mathrm{ml}$ at 4 hours and a d/p of creatinine greater than 0.49 .

- Low volume of drainage with medium-low or medium-high transport

\section{Results}

The population of children with ESRD in peritoneal dialysis was 80: 41 male and 39 female. The average age of entry to peritoneal dialysis was 10.3 years, with the lowest age 7 months and the highest age 16 years 6 months. Regarding the distribution by age group, it was found that school children and adolescents accounted for $85 \%$ of all patients in PD (Table 1).

\begin{tabular}{|l|l|l|}
\hline Age group & Frequency & Percentage \\
\hline Less than 2 years & 4 & $5 \%$ \\
\hline $\mathbf{2}$ to 5 years & 8 & $10 \%$ \\
\hline $\mathbf{5}$ to $\mathbf{2}$ years & 35 & $43.7 \%$ \\
\hline Older than 12 years & 33 & $41.3 \%$ \\
\hline Total & 80 & $100 \%$ \\
\hline
\end{tabular}

Table 1: Distribution of the 80 children on chronic peritoneal dialysis by age group

The most frequently used peritoneal dialysis modality was CAPD (continuous ambulatory peritoneal dialysis) in 67 children (83.8\%).

The most common primary diagnosis of ESRD were the primary glomerulopathies and obstructive uropathies (Table 2).

\begin{tabular}{|l|l|l|}
\hline Type of nephropathy & Frequency & Percentage \\
\hline Primary glomerulopathy & 39 & $48,8 \%$ \\
\hline Obstructive uropathy & 22 & $27.5 \%$ \\
\hline Secondary glomerulopathy & 9 & $11.2 \%$ \\
\hline Congenital: hypoplasia or renal dysplasia & 8 & $10 \%$ \\
\hline Hereditary & 2 & $2.5 \%$ \\
\hline Total & 80 & $100 \%$ \\
\hline
\end{tabular}

Table 2: Common causes of ESRD resulting in chronic peritoneal dialysis in the population of 80 children at Cayetano Heredia National Hospital

Regarding the type of catheter used, the three most common were the Tenckhoff two-cuff spiral catheter, the Tenckhoff two-cuff straight catheter, and the Tenckhoff one-cuff spiral catheter (Table 3).

Eleven children required catheter replacement: a single replacement was performed on 10 children and two replacements were performed 
Page 3 of 5

on one child. The most frequent reasons for replacement were infectious complications such as peritonitis, and noninfectious complications such as catheter obstruction (Table 4).

\begin{tabular}{|l|l|l|l|}
\hline \multicolumn{2}{|l|}{ Type of PD catheter } & Frequency & Percentage \\
\hline Tenckhoff spiral catheter & 56 & $60.9 \%$ \\
\hline Tenckhoff & two-cuff straight catheter & 21 & $22.8 \%$ \\
\hline Tenckhoff & one-cuff spiral catheter & 14 & $15.2 \%$ \\
\hline Tenckhoff & one-cuff straight catheter & 1 & $1.1 \%$ \\
\hline Goose-neck catheter & 0 & $0 \%$ \\
\hline Total & 92 & $100 \%$ \\
\hline
\end{tabular}

Table 3: Type of peritoneal dialysis catheter inserted in 80 children with ESRD

\begin{tabular}{|l|l|l|}
\hline Causes of catheter replacement & Frequency & Percentage \\
\hline Peritonitis & 5 & $41.7 \%$ \\
\hline Peritonitis candida & 2 & $16.7 \%$ \\
\hline Catheter obstruction & 2 & $16.7 \%$ \\
\hline Catheter migration & 1 & $8.3 \%$ \\
\hline Membrane failure & 1 & $8.3 \%$ \\
\hline Other & 1 & $8.3 \%$ \\
\hline Total & 12 & $100 \%$ \\
\hline
\end{tabular}

Table 4: Causes of catheter replacement in 80 children with ESRD on peritoneal dialysis

In our study over a period of 1968 months follow 92 catheters of chronic peritoneal dialysis were placed, the frequency of noninfectious complications was $40.3 \%$ of children [13]. The incidence was one complication each dialysis every 61.5 months.

The most common noninfectious complications were failure of ultrafiltration (low transporter type), umbilical hernia, catheter obstruction, hemoperitoneum, extrusion of the external catheter cuff, inguinal hernia, leakage of dialysate, abdominal wall hematoma and failure of ultrafiltration (high transporter type), and migration of the catheter (Table 5).

\begin{tabular}{|l|l|l|}
\hline Noninfectious complication & Frequency & Percentage \\
\hline Ultrafiltration failure, low transporter type & 6 & $18.8 \%$ \\
\hline Umbilical hernia & 5 & $15.6 \%$ \\
\hline Obstruction of the PD catheter & 5 & $15.6 \%$ \\
\hline Hemoperitoneum & 4 & $12.5 \%$ \\
\hline Extrusion of the external cuff & 4 & $12.5 \%$ \\
\hline Inguinal hernia & 3 & $9.4 \%$ \\
\hline Leakage of dialysate & 2 & $6.3 \%$ \\
\hline Abdominal wall hematoma & 1 & $3.1 \%$ \\
\hline
\end{tabular}

\begin{tabular}{|l|l|l|}
\hline Ultrafiltration failure, high transporter type & 1 & $3.1 \%$ \\
\hline Migration of the catheter & 1 & $3.1 \%$ \\
\hline Total & 32 & $100 \%$ \\
\hline
\end{tabular}

Table 5: Frequency of non-infectious complications in the population of 80 children with ESRD on peritoneal dialysis

The study found as follows: of eight patients that presented abdominal hernia after the introduction of the catheter, three (37.5\%) had a history of abdominal surgery; of three children who presented leakage of dialysate, two $(66.7 \%)$ had had prior abdominal surgery; of seven children who presented ultrafiltration failure, seven $(100 \%)$ had a history of peritonitis; of eight children who presented abdominal hernia, eight suffered from malnutrition and their albumin value was less than $3.5 \mathrm{mg} / \mathrm{dL}$; of four children that presented outer cuff extrusion, three $(75 \%)$ had a Tenckhoff two-cuff straight catheter. Finally, it was found that of 73 children who had no obstruction of the PD catheter, 71 (97.3\%) had had a partial omentectomy (Table 5).

\section{Discussion}

Cayetano Heredia National Hospital is the only treatment center in Peru for chronic peritoneal dialysis where children with ESRD receive treatment through the Integral Insurance of Health (SIS) of the Ministry of Health.

In the study period of eight years, the population of children was 80 . The average age at entry to PD was 10.3 years, which is similar to ages reported by a number of other studies: 8.2 years in Chile, 9 years in the USA, and 9.1 years in Turkey $[11,15]$.

The present study reports the causes of ESRD in children receiving peritoneal dialysis and found that primary glomerulopathies was the most common. The study by Macchini et al. [10] reports the same finding, while in other studies obstructive uropathy and renal dysplasia predominate.

We found that the most frequent dialysis modality was chronic ambulatory peritoneal dialysis, as in other studies. These findings are similar to a Latin American study [13].

The Tenckhoff two-cuff spiral catheter was the most widely used, omentectomy was performed in $95 \%$ of patients, and the interval between the placement of the catheter and the beginning of PD was two weeks.

The causes of catheter replacement were infections, above all peritonitis and obstruction, as reported by other studies $[10,12,15]$.

The frequency of noninfectious complications was $40.3 \%$ in 80 children over a period of eight years. This frequency is similar to that found in two Italian studies: Manchini et al. [10] report a frequency of $41 \%$ in 78 children over 17 years (1986-2002), and Rinaldi et al. [12] report a frequency of $33 \%$ in 363 children over 15 years (1986-2000). The latter study has more patients as it is based on the Italian registry of children with chronic peritoneal dialysis.

The opposite was found in a study from Brazil, where the frequency of non-infectious complications was $93 \%$. The most frequent complications in the Brazilian study were failure of ultrafiltration, umbilical hernia, and obstruction; in others obstruction was also a 
frequent complication, but not failure of ultrafiltration or umbilical hernia $[10,27]$.

In our study, we found that some complications, such as abdominal hernia and leakage of dialysate, could be related to a history of abdominal surgery. Malnutrition and low serum albumin would relate to the presence of abdominal hernias. Ultrafiltration failure could be linked to a history of peritonitis; in the same manner, there might also be a relation between extrusions of the external cuff and the type of catheter used, such as the Tenckhoff two-cuff straight catheter [28-33]. Partial omentectomy at the time of putting the catheter in place could help prevent

obstruction, as already described in the literature: Macchini et al. [10], for example, found an association between omentectomy and no obstruction of the catheter $(\mathrm{p}<0.02)$.

Therefore, we can conclude that the characteristics of pediatric patients and their noninfectious complications related to chronic peritoneal dialysis therapy in this series, excluding metabolic complications and electrolytes, are similar to those of other studies.

\section{References}

1. Oreopoulos DG, Katirtzoglou A, Arbus G, Cordy P (1979) Dialysis and transplantation in young children. Br Med J 1: 1628-1629.

2. Neu AM, Ho PL, McDonald RA, Warady BA (2002) Chronic dialysis in children and adolescents. The 2001 NAPRTCS Annual Report. Pediatr Nephrol 17: 656-663.

3. van der Heijden BJ1, van Dijk PC, Verrier-Jones K, Jager KJ, Briggs JD (2004) Renal replacement therapy in children: data from 12 registries in Europe. Pediatr Nephrol 19: 213-221.

4. Alexander SR, Salusky IB, Warady BA, Watkins SL (1997) Peritoneal dialysis workshop: pediatrics recommendations. Perit Dial Int 17 Suppl 3: S25-27.

5. Salusky IB, Holloway M (1997) Selection of peritoneal dialysis for pediatric patients. Perit Dial Int 17 Suppl 3: S35-37.

6. Lingens N, Soergel M, Loirat C, Busch C, Lemmer B, et al. (1995) Ambulatory blood pressure monitoring in paediatric patients treated by regular haemodialysis and peritoneal dialysis. Pediatr Nephrol 9: 167-172.

7. Demuner MS (2001) Tenckhoff catheter implant in children with end stage renal disease: technical aspects, surgical non-infectious complications and catheter survival. Tesis of doctor. Sao Paulo, Brasil. Federal University of Sao Paulo - Escola Paulista de Medicina 170 pp.

8. Garcia V, Santos F, Bernardo R (2006) Chapter 68: Chronic Peritoneal Dialysis. In: Pediatric nephrology. 2nd Edition. Madrid - Spain. Publishing Group Aula Medical P: 759 - 762.

9. Stuart S, Booth TC, Cash CJ, Hameeduddin A, Goode JA, et al. (2009) Complications of continuous ambulatory peritoneal dialysis. Radiographics 29: 441-460.

10. Macchini F, Valadè A, Ardissino G, Testa S, Edefonti A, et al. (2006) Chronic peritoneal dialysis in children: catheter related complications. A single centre experience. Pediatr Surg Int 22: 524-528.

11. Rahim KA, Seidel K, McDonald RA (2004) Risk factors for catheterrelated complications in pediatric peritoneal dialysis. Pediatr Nephrol 19: 1021-1028.

12. Rinaldi S, Sera F, Verrina E, Edefonti A, Gianoglio B, et al. (2004) Chronic peritoneal dialysis catheters in children: a fifteen-year experience of the Italian Registry of Pediatric Chronic Peritoneal Dialysis. Perit Dial Int 24: 481-486.

13. Cavagnaro S.M, Lagomarsino F (1997) Chronic child peritoneal dialysis current status in Chile Rev. Chil. Pediatr 68: 78-82
14. Prasad N, Gulati S, Gupta A, Sharma RK, Kumar A, et al. (2006) Continuous peritoneal dialysis in children: a single-centre experience in a developing country. Pediatr Nephrol 21: 403-407.

15. Nejat A, Onder Y, Murat A, OrhanDeniz K, Hakan E, et al. (2007) A tenyear single-center experience in children on chronic peritoneal dialysissignificance of percutaneous placement of peritoneal dialysis catheters. Nephrol Dial Transplant 22: 2045-2051.

16. Poux JM, Bénévent D, Guiserix J, Le Meur Y, Lagarde C, et al. (1994) [Chylous ascites in 12 patients undergoing peritoneal dialysis]. Nephrologie 15: 201-205.

17. Jain S, Cropper L, Rutherford P (2003) Chylous ascites due to bile duct tumour in a patient receiving automated peritoneal dialysis. Nephrol Dial Transplant 18: 224.

18. Pérez Fontan M, Pombo F, Soto A, Pérez Fontan FJ, Rodriguez-Carmona A (1993) Chylousascites associated with acute pancreatitis in a patient undergoing continuous ambulatory peritoneal dialysis. Nephron 63: $458-61$.

19. Coronel F, Aviles B (2003) Chyloperitoneum in a peritoneal dialysis patient with primary AL amyloidosis. Perit Dial Int 23: 299-301.

20. Huang CH, Chen HS, Chen YM, Tsai TJ (1996) Fibroadhesive form of tuberculous peritonitis: chyloperitoneum in a patient undergoing automated peritoneal dialysis. Nephron 72: 708-711.

21. Yoshimoto K, Saima S, Nakamura Y, Nakayama M, Kubo H, et al. (1998) Dihydropyridine type calcium channel blocker-induced turbid dialysate in patients undergoing peritoneal dialysis. Clin Nephrol 50: 90-93.

22. Del Peso G, Bajo MA, Costero O, Hevia C, Gil F, et al. (2003) Risk factors for abdominal wall complications in peritoneal dialysis patients. Perit Dial Int 23: 249-254.

23. Van Dijk CM, Ledesma SG, Teitelbaum I (2005) Patient characteristics associated with defects of the peritoneal cavity boundary. Perit Dial Int 25: 367-373.

24. Mahale AS, Katyal A, Khanna R (2003) Complications of peritoneal dialysis related to increased intra-abdominal pressure. Adv Perit Dial 19: 130-135.

25. Mujais S, Nolph K, Gokal R, Blake P, Burkart J, et al. (2000) Evaluation and management of ultrafiltration problems in peritoneal dialysis. International Society for Peritoneal Dialysis Ad Hoc Committee on Ultrafiltration Management in Peritoneal Dialysis. Perit Dial Int 20 Suppl 4: S5-21.

26. Twardowski ZJ, Nolph K, Khanna R, Prowant B, Ryan L, et al. (1987) Peritoneal equilibration test. Perit. Dial. Bull 7:138-47.

27. Greenberg A, Bernardini J, Piraino BM, Johnston JR, Perlmutter JA (1992) Hemoperitoneum complicating chronic peritoneal dialysis: singlecenter experience and literature review. Am J Kidney Dis 19: 252-256.

28. Dozio B, Scanziani R, Rovere G, Sangalli L, Sacerdoti S, et al. (2001) Hemoperitoneum in a continuous ambulatory peritoneal dialysis patient caused by a hepatocarcinoma treated with percutaneous embolization. Am J Kidney Dis 38: E11.

29. Nolph KD, Twardowski ZJ, Popovich RP, Rubin J (1979) Equilibration of peritoneal dialysis solutions during long-dwell exchanges. J Lab Clin Med 93: 246-256.

30. Pannekeet MM, Imholz AL, Struijk DG, Koomen GC, Langedijk MJ, et al. (1995) The standard peritoneal permeability analysis: a tool for the assessment of peritoneal permeability characteristics in CAPD patients. Kidney Int 48: 866-875.

31. Ho-dac-Pannekeet MM, Atasever B, Struijk DG, Krediet RT (1997) Analysis of ultrafiltration failure in peritoneal dialysis patients by means of standard peritoneal permeability analysis. Perit Dial Int 17: 144-150.

32. Krediet RT, Struijk DG, Boeschoten EW, Koomen GC, Stouthard JM, et al. (1989) The time course of peritoneal transport kinetics in continuous ambulatory peritoneal dialysis patients who develop sclerosing peritonitis. Am J Kidney Dis 13: 299-307.

33. Hendriks PMEM, Ho-dac-Pannekeet MM, Van Gulik TM, StruijK DG (1997) Peritoneal sclerosis in chronic peritoneal dialysis patients: analysis 
Citation: Loza R, Gutarra E (2014) Noninfectious Complications in Children Undergoing Chronic Peritoneal Dialysis. J Nephrol Ther 4: 163. doi: 10.4172/2161-0959.1000163

Page 5 of 5

of clinical presentation, risk factors and peritoneal transport kinetics.

Perit Dial Int 17: 136-43. 